\section{$\underset{\substack{\text { hommes } \\ \text { \& migrations }}}{ }$}

\section{Hommes \& migrations}

Revue française de référence sur les dynamiques

migratoires

1329 | 2020

Migrations et création littéraire

\title{
Yancouba Diémé, Boy Diola
}

Flammarion, Paris, 2019, 192 pages, 17 euros.

\section{(2) OpenEdition}

1 Journals

Édition électronique

URL : https://journals.openedition.org/hommesmigrations/11306

DOI : 10.4000/hommesmigrations. 11306

ISSN : 2262-3353

Éditeur

Musée national de l'histoire de l'immigration

Édition imprimée

Date de publication : 1 avril 2020

Pagination : 198

ISBN : ISBN 978-2-919040-50-6

ISSN : 1142-852X

Référence électronique

«Yancouba Diémé, Boy Diola », Hommes \& migrations [En ligne], 1329 | 2020, mis en ligne le 01 avril 2020, consulté le 04 janvier 2023. URL : http://journals.openedition.org/hommesmigrations/11306 ; DOI : https://doi.org/10.4000/hommesmigrations. 11306 


\section{Boy Diola}

Yancouba Diémé, Paris, Flammarion, 2019, 192 pages, 17 euros.

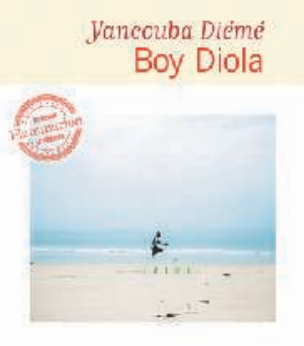

Le roman commence sur le silence d'Aperaw, le père de Yancouba Diémé. Ou plutôt sur son refus de raconter son histoire à son fils. Toutefois, c'est bien dans ces premières pages qu'un espace de parole se crée: entre refus de se raconter et désir de transmettre; refus de se replonger dans une mémoire migratoire et désir d'enraciner ses enfants dans leurs origines. L'histoire se déploie ainsi dans l'interstice de ce paradoxe inaugural. Encouragé par la curiosité de son fils, Aperaw finit par se raconter. Les souvenirs s'enchaînent: les «huit jours de traversée», les interminables heures d'attente à la préfecture de Bobigny, l'achat à crédit de la maison à Aulnay-sousBois en 1985, le mariage au Sénégal en 1972, l'arrivée de l'épouse en France en 1974, le mariage avec la seconde épouse en 1986, le décès de la première épouse en 1997, le travail dans les ateliers de Citroën à partir de 1977, les premières grèves en 1982, le licenciement en 1991, la vie dans les foyers de travailleurs, la vente sur les marchés, le retour à la cité des 3000 après expulsion du pavillon, la sécheresse du Sahel dans les années 1960, le départ pour Dakar dans les années 1950, le séjour prolongé à Abidjan et en Gambie, la naturalisation française en 2010, le départ en bateau pour la France, le retour au Sénégal pour y passer sa retraite, etc.

Une alternance des points de vue narratifs vient rythmer et préciser ces souvenirs. Les voix du père et du fils se superposent et s'éclairent mutuellement, semblant mimer ainsi l'entremêlement des destins individuels. S'appuyant sur des bribes de récits, des photos, des lettres et des entretiens, le fils retrace minutieusement l'histoire de son père et l'histoire familiale.

Le respect et la tendresse du fils à l'égard de son père transparaissent dans le récit sans grande pudeur. Yancouba rend hommage à son père, qu'il montre comme un homme courageux et volontaire ayant affronté des obstacles sans défaillir. Mais l'histoire, plus humble, du quotidien n'est pas pour autant éludée. L'on voit Aperaw devant son poste de télévision, à regarder des documentaires animaliers, décortiquer des arachides avec dextérité, ou encore, dans le chapitre final, s'émerveiller devant le but de Mario Balotelli - ce footballeur italien, né à Palerme de parents ghanéens - en 2012, oubliant ce faisant qu'il vient de se faire humilier par des cris de singe et des bananes lancés depuis les tribunes.

Boy Diola nous plonge ainsi dans une mémoire individuelle et familiale. Nous sommes suspendus à la voix et aux souvenirs du père, ballottés entre le temps du récit et «le temps de avant-avant». Ballottés également par les allées et venues narratives entre les différents espaces (la France, le Sénégal, la Gambie, la Côte d'Ivoire, etc.), pris dans ce mouvement continu qui retrace le parcours et la mémoire migratoires d'un homme. Théoxane Camara, doctorante en sociologie (Gresco), université de Poitiers. 